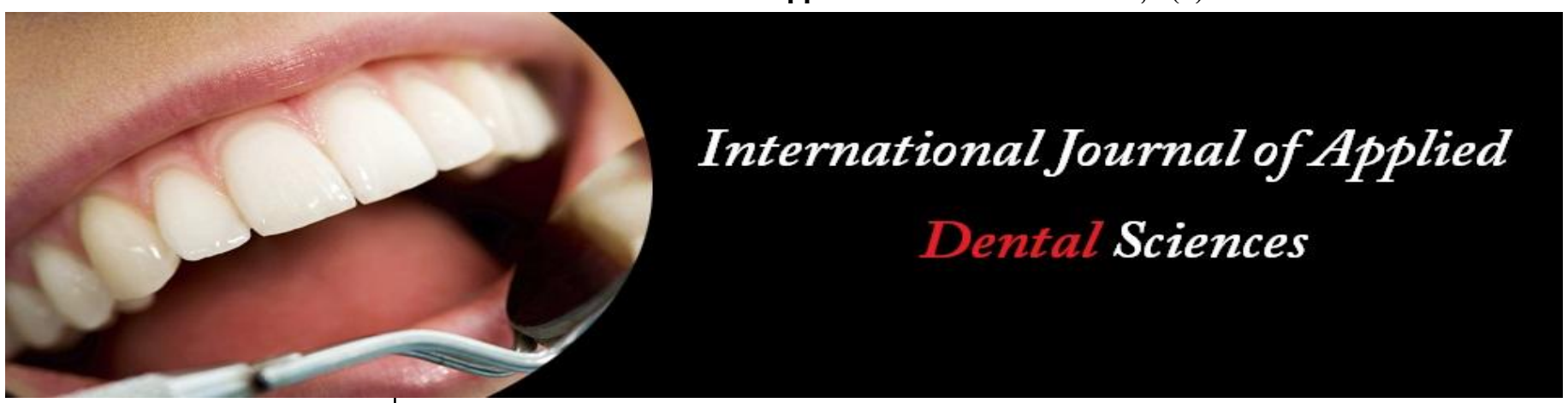

ISSN Print: 2394-7489

ISSN Online: 2394-7497

IJADS 2018; 4(4): 342-345

(C) 2018 IJADS

www.oraljournal.com

Received: 25-08-2018

Accepted: 27-09-2018

Mustafa Gündoğar

$\mathrm{PhD}$, Istanbul Medipol

University, Department of

Endodontics., Istanbul, Turkey

Güzide Pelin Sezgin

PhD, Biruni University, Faculty

of Dentistry, Department of

Endodontics, Istanbul, Turkey

\section{Cyclic Fatigue Resistance of Genius, RC Gold and Revo-S Nickel-titanium Instruments}

\section{Mustafa Gündoğar and Güzide Pelin Sezgin}

\section{Abstract}

Aim: To compare the cyclic fatigue resistance of Revo-S, Genius, and RC Gold Primary files using static cyclic fatigue test device.

Materials and Methods: Twenty Revo-S (25/.06), 20 Genius (25/.04), and 20 RC Gold (25/.08) instruments were included in this study. The cyclic fatigue tests were performed using a cyclic fatigue testing device, which has an artificial stainless-steel canal with a $60^{\circ}$ angle of curvature and a $5-\mathrm{mm}$ radius of curvature. The files were randomly divided into 3 groups (group 1: Revo-S; group 2: Genius; and group 3: RC Gold). All the instruments were rotated until fracture occurred, and the time to fracture was recorded in seconds using a digital chronometer. The number of cycles to failure (NCF) and the length of the fractured segments were calculated. The data were analyzed statistically using KruskalWallis test $(P<.05)$.

Results: There was a significant difference among the groups $(P<.05)$. The Genius showed the greatest mean of NCF $(4155.22 \pm 139.55)$, and the Revo-S showed the lowest mean of NCF $(1480.60 \pm 118.92)$.

Conclusions: Within the limitations of this in vitro study, the cyclic fatigue resistance of the Genius system was higher than the Revo-S and RC Gold instruments.

Keywords: Cyclic fatigue resistance, Endodontics, Revo-s, static model, RC gold

\section{Introduction}

Nickel-titanium (Ni Ti) files are widely used in the preparation of especially the curved canals due to their high flexibility and excellent cutting abilities ${ }^{[1]}$. Despite their superior properties, the fracture risk of $\mathrm{Ni}$ Ti rotary files, especially in curved canals, has been a problem for the dentists. The removal of the fractured segment from the root canal is a hard process and the amount of remaining dentine after the process is also reduced. This situation negatively affects the prognosis of the endodontic treatment ${ }^{[2]}$. Ni Ti rotary file systems are mostly fractured depending on the either torsional or cyclic fatigue ${ }^{[3]}$. Manufacturers strive to increase the fracture resistance of $\mathrm{Ni} \mathrm{Ti}$ files by altering designs, altering various heat treatments and using different types of alloys ${ }^{[4]}$. Also; modification in the kinematics of the NiTi files may change the resistance of the files against fracture. It has been shown that the stress occurring on the files performing preparation with reciprocation motion is less than the stress occurring on the files performing preparation with the rotation motion and in this way, the files performing reciprocation motion were more resistance against cyclic fatigue ${ }^{[5]}$.

RC Gold (Perfect Medical Instruments, Shenzhen, China) rotary system is the single-file system with reciprocation motion. It has an S-shaped cross section, 2 cutting edges and has been made of M-Wire alloy. It has three files as R25 (25/.08), R40 (25/.06), and R50 (25/.05) ${ }^{[6]}$. Genius (GF; Ultradent, Utah, the USA) is file system recently launched to market. It has been made of heat-treated NiTi alloy and operates as based on both reciprocation and rotation motions. The manufacturer suggests the usage of $0.25 \mathrm{~mm}$ apical diameter file with the reciprocal motion and other files (at the point of D0 with the diameter of $0.30,0.35,0.40$ and $0.50 \mathrm{~mm}$ ) with rotation motion. The reciprocal motion of Genius file is different from RC Gold file. Genius file conducts the reciprocal motion firstly in clockwise direction and then, in counterclockwise direction and the reciprocation angle $\left(90^{\circ}\right.$ in clockwise direction and $30^{\circ}$ in counterclockwise direction) is less than RC Gold file ${ }^{[7]}$.

Revo-S (Micro Mega, Besancon, France) is a file system made of traditional NiTi alloy and this system consists of 6 files (SC1, SC2, SU, AS30, AS35 and AS40).

\section{Correspondence}

PhD, İstanbul Medipol

University, Department of

Endodontics., Istanbul, Turkey 
It performs like snake motion owing to its asymmetrical cross section and in this way; according to the manufacturer, it shows resistance against cyclic fatigue ${ }^{[8]}$.

In a comprehensive literature review, no study could be found comparing the resistance of Genius Files, RC Gold File and Revo-S NiTi files against cyclic fatigue. The aim of this study was to examine the resistance of three different NiTi file systems with various metallurgy and kinematics against cyclic fatigue. The null hypothesis of the study was that there would be no difference among the resistances of the NiTi files against cyclic fatigue.

\section{Materials and Methods}

20 Genius (25/.04), 20 RC Gold (25/.08) and 20 Revo-S (25/.06) files were included in the present study. Artificial canals made of stainless steel with 5 -mm radius of curvature, $60^{\circ}$ angle of curvature and 1,5-mm inner diameter was used for the cyclic fatigue test ${ }^{[9]}$. Besides; the center of the curvature was positioned in $5 \mathrm{~mm}$ coronal of the apical outcome point of the artificial canals. In all of the groups, synthetic lubricant (WD-40 Company, Milton Keynes, England) was used for the minimizing the friction between the files and artificial canal walls and be able to free motion of files in the artificial canals. The top of the stainless-steel block was covered with glass in order to better observe the fracture of files.

Files were divided into three test groups and the following procedures were performed:

\section{Group 1: RC Gold File (25/.08)}

The files in this group were used until the fracture occurred in Reciproc ALL program with VDW Gold (VDW, Munich, Germany) endodontic motor mounted on cyclic fatigue test device.

\section{Group 2: Revo-S File (25/.06)}

The files in this group were used until the fracture with occurred at $300 \mathrm{rpm}$ and $2 \mathrm{~g} / \mathrm{cm}$ torque with VDW Gold (VDW) endodontic motor mounted on the cyclic fatigue test device.

\section{Group 3: Genius File (25/.04)}

The files in this group were used until fracture occurred with Endo EZE Genius (Ultradent) endodontic motor mounted on the cyclic fatigue test device. The "Reciprocation" program $\left(90^{\circ}\right.$ clockwise and $30^{\circ}$ counter clockwise movements at 350 rpm) was used until fracture occurred.

All files were used in artificial canals until fracture occurred and the time to fracture was recorded with digital chronometer. Then, the number of cycles until the fractured occurred (NCFS) were calculated with the formula upon the obtained time $(\mathrm{NCFS}=$ revolutions per minute $(\mathrm{rpm}) \mathrm{x}$ time to fracture $(\mathrm{sec}) / 60)$. The lengths of the fractured parts were measured with a digital caliper. A total of six files ( $n$ : 2 for each group) were examined under scanning electron microscope (JEOL, JSM-7001F, Tokyo, Japan) in order to confirm that the files fractured depending on cyclic fatigue.

\section{Statistical Analysis}

The data were firstly analyzed using Shapiro-Wilk test in order to verify normally distribution. Then, the statistical analysis of the data was performed with Kruskal-Wallis test using SPSS 21.0 (IBM-SPSS Inc., Chicago, IL, USA) program. Statistical significance level was set as $5 \%$.

\section{Results}

The means and standard deviations of the NCF values and the lengths of fractured segments are shown in in Table 1. Genius file $(4155.22 \pm 139.55)$ had significantly the highest resistance against cyclic fatigue, and Revo-S file $(1480.60 \pm 118.92)$ had significantly lowest resistance against cyclic fatigue $(P<.05)$. There was no significant difference $(P>.05)$ in the mean length of the fractured fragments of the files (Table 1). When the images of the fracture surfaces were examined with the scanning electron microscope, the fatigue lines were observed in all groups (Figure 1).

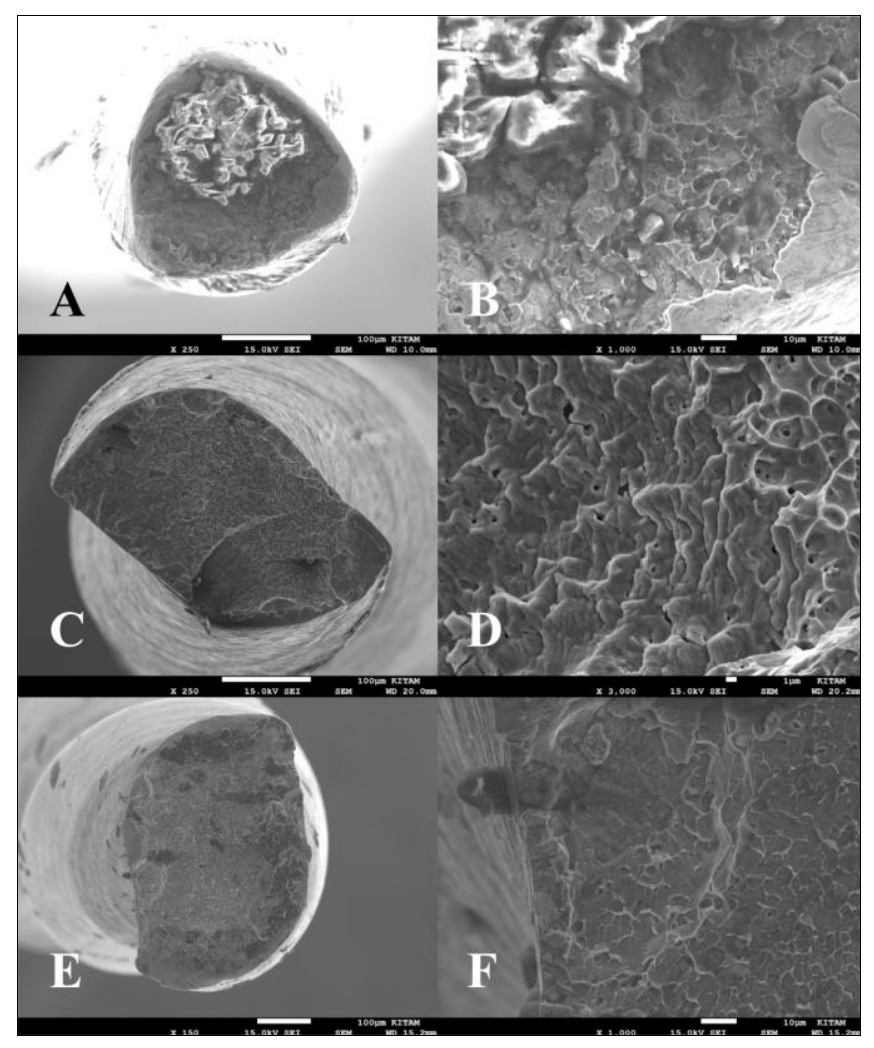

Fig 1: SEM appearances of the Revo-S, Genius and RC Gold files after cyclic fatigue testing. General view of Revo-S (A), Genius (C) and RC Gold (E) instrument with crack origins. High-magnification view Revo-S (B), Genius (D) and RC Gold (F) instrument showing fatigue striations typical of cyclic fatigue.

Table 1: Number of cycles to failure (means and standard deviations) of two groups during cyclic fatigue test

\begin{tabular}{|c|c|c|c|}
\hline \multirow{2}{*}{ Group } & \multicolumn{2}{|c|}{ NCF } & $\begin{array}{c}\text { Fractured } \\
\text { length (mm) }\end{array}$ \\
\cline { 2 - 4 } & Mean & Standard Deviation & $5.63 \pm 0.54$ \\
\hline RC Gold & $2785.89^{\mathrm{a}}$ & 105.35 & $5.02 \pm 0.52$ \\
\hline Revo-S & $1480.60^{\mathrm{b}}$ & 118.92 & $5.72 \pm 0.53$ \\
\hline Genius & $4155.22^{\mathrm{c}}$ & 139.55 & $>.05$ \\
\hline$P$-value & \multicolumn{2}{|c|}{$<.05$} & \\
\hline
\end{tabular}

* Different superscripts letter was statistically significant $(P<.05)$.

\section{Discussion}

One of the most important problems experienced by the dentists in clinical practice is the files fracture during endodontic treatment. This situation may negatively affect the success of the root canal treatment ${ }^{[10]}$. The files fracture during the clinical usage were stated fracture occurred mostly due to cyclic fatigue ${ }^{[1,12]}$. Many studies were conducted on the resistance of NiTi rotary files against cyclic fatigue ${ }^{[13,14]}$. Manufacturers aim to improve the cyclic fatigue resistance of the files by applying heat treatments to files as well as modifying their design, metallurgy and kinematics ${ }^{[15,16]}$. For 
this reason; in the present study, the cyclic fatigue resistance of three different (Genius, RC Gold, Revo-S) NiTi rotary files with different metallurgy and kinematics were compared. According to the results of the study, Genius file was found to be significantly more resistant against cyclic fatigue than RC Gold File and Revo-S files. Therefore; the null hypothesis of the study was rejected. No significant difference was found among the lengths of the fractured parts. This showed that the tested NiTi files were positioned correctly in the canal curvature and similar stresses were induced. No complete standardization of the cross-sections, dimensions and metallurgies of the files forms a disadvantage for the laboratory studies examining the cyclic fatigue resistance ${ }^{[17]}$. Although the usage of the extracted human teeth in cyclic fatigue studies reflects the clinical conditions better, standardization of the anatomic variations of teeth could not be possible ${ }^{[18]}$. For this reason, standard artificial canals made of stainless steel were used in this study.

According to the results of the study, Genius file showed the highest cyclic fatigue resistance. Similarly, it was specified in the study conducted by Özyürek et al. that the resistance of Genius file against cyclic fatigue was higher than Reciproc Blue (RPC Blue; VDW) and Wave One Gold (WOG; Dentsply Sirona, Baillagues, Switzerland) files. Özyürek et al. expressed that this difference resulted from the diameter and reciprocation angle of GF file to be less than RPC Blue and WOG files. Because there was no study examining the resistance of RC Gold file against cyclic fatigue, the results of this study could not be directly compared with the other study results. It was specified in the previous studies that the reciprocation motion increased the cyclic fatigue resistance of NiTi files when compared to the rotary motion ${ }^{[19-21]}$. This result shows similarities with the results of present study. According to the results of present study; the fact that the Genius file showed higher resistance than RC Gold file against cyclic fatigue is considered to result from the lowness of the reciprocal motion angle and taper of the file.

Çapar et al. compared the fracture resistances of Pro Taper Next (Dentsply Sirona), Hy Flex CM (Coltene-Whaledent, Allstetten, Switzerland), One Shape (Micro Mega) and Revo$\mathrm{S}$ NiTi files depending on cyclic fatigue and expressed that Revo-S file made of traditional NiTi alloy showed the lowest cyclic fatigue resistance. It was believed that the reason for this result originates from the alloys used in the manufacturing procedure ${ }^{[22]}$. In contrast to this study; the cyclic fatigue resistance of Pro Taper Next, Gentle file (Medic NRG, Kibbutz Afikim, Israel) and Revo-S NiTi files were compared by Moreinoset et al. and authors stated that there was no significant difference between Pro Taper Next and Revo-S. The reason of this could be referred to the methodological differences between the two studies [23]. Pedullà et al. examined the cyclic fatigue resistances of Twisted File (Sybron Endo, Orange, CA, USA), Bio Ra Ce (FKG, La Chaux de Fonds, Switzerland), Mtwo (VDW) and Revo-S NiTi files. They expressed that Revo-S and Bio Ra Ce files had the lowest cyclic fatigue resistance and the reason for this had based on the difference of the sections of the files [24]. Similarly; in the study of Lopes et al. in which the cyclic fatigue resistance of K3 (Sybron Endo, Orange, CA), K3XF (Sybron Endo), Pro File Vortex (Dentsply Tulsa Dental, Tulsa, OK) and Revo-S NiTi files was compared, it was reported that Revo-S files showed the lowest cyclic fatigue resistance. This result was based on the difference among the alloys of the files ${ }^{[25]}$. According to the results of present study, the fact that Revo-S files showed the lowest cyclic fatigue resistance is considered to originate from the conventional NiTi alloy used in manufacturing process and its kinematics to be rotation.

\section{Conclusion}

Within the limitations of the present in vitro study, Genius instruments resisted static cyclic fatigue significantly more than RC Gold and Revo-S instruments.

\section{References}

1. Shen Y, Zhou HM, Zheng YF et al. Current challenges and concepts of the thermo mechanical treatment of nickel-titanium instruments. J Endod. 2013; 9:163-72.

2. Yang Q, Shen Y, Huang D, Zhou X, Gao Y, Haapasalo M. Evaluation of Two Trephine Techniques for Removal of Fractured Rotary Nickel-titanium Instruments from Root Canals. J Endod. 2017; 43:116-20.

3. Sattapan B, Nervo GJ, Palamara JE, Messer HH. Defects in rotary nickel-titanium files after clinical use. J Endod. 2000; 26:161-5.

4. Peters O, Gluskin A, Weiss R, Han J. An in vitro assessment of the physical properties of novel Hyflex nickel-titanium rotary instruments. Int Endod J. 2012; 45:1027-34.

5. Ferreira F, Adeodato C, Barbosa I, Aboud L, Scelza P, Zaccaro Scelza M. Movement kinematics and cyclic fatigue of NiTi rotary instruments: a systematic review. Int Endod J. 2016; 50:143-52.

6. RC Gold System brochure. Available at: http://www.dental-perfect.com/sale-10339380-rc-goldreciprocating-endo-files-niti-rotary-instruments-inendodontics.html. Accessed 2018, December.

7. Özyürek T, Gündoğar M, Yılmaz K, Uslu G. Bending resistance and cyclic fatigue life of Reciproc Blue, Wave One Gold, and Genius files in a double (S-shaped) curved canal. J Dent Res Dent Clin Dent Prospects. 2017; 11:241-6.

8. Revo-S Brochure. Available at: http://micromega.com/en/wp-content/uploads/2012/10/MMRevoS_brochure.pdf. Accessed 2018, December.

9. Gündoğar M, Özyürek T. Cyclic fatigue resistance of One Shape, Hy Flex EDM, Wave One gold, and Reciproc blue nickel-titanium instruments. J Endod. 2017; 43:1192-6.

10. Shahabinejad H, Ghassemi A, Pishbin L, Shahravan A. Success of ultrasonic technique in removing fractured rotary nickel-titanium endodontic instruments from root canals and its effect on the required force for root fracture. J Endod. 2013; 39:824-8.

11. Cheung G, Peng B, Bian Z et al. Defects in Pro Taper S1 instruments after clinical use: fractographic examination. Int Endod J. 2005; 38:802-9.

12. Inan U, Gonulol N. Deformation and fracture of Mtwo rotary nickel-titanium instruments after clinical use. J Endod. 2009; 35:1396-9.

13. Özyürek T. Cyclic fatigue resistance of Reciproc, Wave One, and Wave One Gold nickel-titanium instruments. J Endod. 2016; 42:1536-9.

14. Topçuoğlu HS, Topçuoğlu Aktı A. In vitro comparison of cyclic fatigue resistance of Pro Taper Next, Hy Flex CM, One Shape, and Pro Taper Universal instruments in a canal with a double curvature. J Endod. 2016; 42:969-71.

15. Ferreira F, Adeodato C, Barbosa I et al. Movement kinematics and cyclic fatigue of NiTi rotary instruments: a systematic review. Int Endod J. 2016; 50:143-52. 
16. Shen Y, Zhou HM, Zheng YF et al. Current challenges and concepts of the thermo- mechanical treatment of nickel-titanium instruments. J Endod. 2013; 39:163-72.

17. Cheung G, Zhang E, Zheng Y. A numerical method for predicting the bending fatigue life of NiTi and stainless steel root canal instruments. Int Endod J. 2011; 44:357-61.

18. Yao JH, Schwartz SA, Beeson TJ. Cyclic fatigue of three types of rotary nickel-titanium files in a dynamic model. J Endod. 2006; 32:55-7.

19. De-Deus G, Moreira E, Lopes H, Elias C. Extended cyclic fatigue life of F2 Pro- Taper instruments used in reciprocating movement. Int Endod J. 2010; 43:1063-8.

20. Varela-Patino P, Ibanez-Parraga A, Rivas-Mundina B et al. Alternating versus continuous rotation: a comparative study of the effect on instrument life. J Endod. 2010; 36:157-9.

21. Karatas E, Arslan H, Büker M et al. Effect of movement kinematics on the cyclic fatigue resistance of nickeltitanium instruments. Int Endod J. 2015; 49:361-4.

22. Capar ID, Ertas H, Arslan H. Comparison of cyclic fatigue resistance of novel nickel- titanium rotary instruments. Aust Endod J. 2015; 41:24-8.

23. Moreinos D, Dakar A, Stone NJ, Moshonov J. Evaluation of Time to Fracture and Vertical Forces Applied by a Novel Gentlefile System for Root Canal Preparation in Simulated Root Canals. J Endod. 2016; 42:505-8.

24. Pedullà E, Plotino G, Grande NM, Pappalardo A, Rapisarda E. Cyclic fatigue resistance of four nickeltitanium rotary instruments: a comparative study. Ann Stomatol. 2012; 3:59-63.

25. Lopes HP, Gambarra-Soares T, Elias CN. Comparison of the mechanical properties of rotary instruments made of conventional nickel-titanium wire, M-wire, or nickel-titanium alloy in R-phase. J Endod. 2013; 39:516-20. 